\title{
SISTEM IDENTIFKASI PENYAKIT TANAMAN CABAI MENGGUNAKAN METODE SIMPLE ADDITIVE WEIGHTING (SAW) BERBASIS ANDROID
}

\author{
${ }^{1}$ Hendire S B, ${ }^{2}$ Machudor Yusman \\ 1,2 Jurusan Ilmu Komputer, Fakultas Matematika dan Ilmu Pengetahuan Alam, \\ Universitas Lampung, Lampung, Indonesia \\ e-mail : hendire.socoval@gmail.com
}

\begin{abstract}
Chili is an important commodity in Indoneisa's economy. The fluctuating price causes chili to contribute to inflation for national economy. Chili's price could increase because of demand in high level and production of chili in low level. The emergence of disease causes production of chili decreas. To solve the problem in chili disease, the disease needs to be diagnose as soon as possible. To diagnose the disease as soon as possible there is a need of chili expert system using android. Chili's disease will be indentificated by inputting the symptoms which are shown by the plan. Expert system of chili plant disease identification design is based Android. Android Mobile is used as a device to insert the symptoms which are shown by the plant. The system will manage the symptoms that have been selected and show the diagnoses of the disease and how to control the disease. This system was designed using the Simple Additive Weighting (SAW) method and tested using Blackbox method. Testing using Blackbox method to show the system is able to identify the diseases of chili plant.
\end{abstract}

Keywords: Black Box Testing; CHILI; Chili Disease; Expert System; SAW

\section{PENDAHULUAN}

Cabai merupakan komuditas penting dalam perekonomian Indonesia. Harganya yang selalu fluktuatif, membuat cabai sering menyumbang inflasi bagi perekonomian nasional. [1] Kenaikan harga cabai disebabkan oleh permintaan yang tinggi dan tingkat produksi di petani cabai rendah. Timbulnya suatu penyakit menyebabkan produksi cabai menurun yang disebabkan oleh gagal panen petani cabai. [2] Dalam mengatasi tanaman cabai yang terkena penyakit, penyakit perlu diagnosa sedini mungkin. Proses diagnosa membutuhkan seorang pakar yang ahli dan berpengalaman agar menghasilkan diagnosa yang tepat. Namun demikian, keterbatasan waktu yang dimiliki seorang pakar terkadang menjadi kendala bagi para petani yang akan melakukan konsultasi guna menyelesaikan suatu permasalahan untuk mendapatkan solusi terbaik. Dalam hal ini, sistem pakar dihadirkan sebagai alternatif kedua dalam memecahkan permasalahan setelah seorang pakar [3].

Pengembangan sistem pakar yang dapat mendiagnosa penyakit tanaman cabai berdasarkan gejala-gejalanya dan cara pengendaliannya. Penelitian tersebut memiliki kekurangan yaitu sistem pakar yang dibangun masih berbasis desktop dengan menggunakan PC sehingga kurang praktis dalam penggunaannya, karena hanya dapat digunakan pada komputer stand alone. Sedangkan sistem pakar berbasis android lebih efisien karena lebih mudah diakses di mana saja. [4] Pengembangan penelitian berikutnya sistem pakar yang dapat mendiagnosa hama dan penyakit pada tanaman cabai menggunakan Metode Teorema Bayes berbasis web. Penelitian tersebut memiliki kekurangan yaitu sistem pakar yang dibangun masih berbasis web, sehingga membutuhkan koneksi internet yang stabil agar aplikasi berjalan dengan lancar dan data yang di gunakan masih sedikit. Penelitian [5] Menghasilkan sistem pakar yang dapat mendiagnosa hama dan penyakit pada tanaman cabai menggunakan Metode Forward Chaining berbasis android. Penelitian tersebut memiliki kekurangan yaitu penyakit yang didiagnosa hanya penyakit yang disebabkan oleh jamur.

Penelitian ini dibuat berbasis android menggunakan metode Simple Additive Weighting untuk membuat aplikasi yang lebih menarik dan efisien. Penelitian ini merupakan pembuatan aplikasi Sistem Pakar Penyakit 
Tanaman Cabai. Tujuan dari penelitian ini adalah membangun aplikasi sistem pakar identifikasi penyakit tanaman cabai serta cara pengendaliannya dengan penerapan metode Simple Additive Weighting (SAW) sebagai pengambilan keputusan hasil penyakit berbasis Android . Manfaat yang diperoleh dari penelitian ini, yaitu : Membantu petani cabai dalam mendapatkan informasi untuk menyelesaikan masalah terkait dengan penyakit tanaman cabai serta pengendalian dari penyakit tersebut..

\section{METODOLOGI PENELITIAN}

Dalam mengembangkan suatu sistem pakar diperlukan adanya tahapan penelitian, dimana langkah-langkah yang dilakukan peneliti. Langkah-langkah dalam penelitian ini meliputi perumusan masalah, pengumpulan data, perancangan sistem, pembuatan sistem, dan pengujian sistem.

\subsection{Perumusan Masalah}

Tahapan ini merupakan proses merumuskan dan membatasi masalah yang diteliti. Perumusan dan pembatasan masalah diperlukan agar dapat lebih mengarahkan peneliti dalam membuat sistem sehingga penelitian yang dikerjakan tidak keluar dari batasan yang telah ditetapkan sebelumnya.

\subsection{Pengumpulan Data}

Pengumpulan data merupakan suatu kegiatan mencari data di lapangan yang digunakan untuk menjawab permasalahan penelitian. Oleh karena itu, pengumpulan data serta kualifikasi pengumpul data sangat diperlukan untuk memperoleh data yang berkualitas. Pengumpulan data yang digunakan dalam menyusun serta melengkapi data penelitian ini adalah dengan cara wawancara dan studi pustaka.

\subsection{Perancangan Sistem}

Perancangan sistem dilakukan untuk memberikan gambaran atau perencanaan sistem dalam pembuatan aplikasi sitem pakar diagnosa penyakit tanaman cabai berbasis Android. Perancangan aplikasi sitem pakar diagnosa penyakit tanaman cabai berbasis Android adalah dengan menggunakan software Edraw Max dengan pemodelan UML yang terdiri dari use case diagram, activity diagram,dan perancangan interface aplikasi.

\subsection{Pembuatan Sistem}

Pada tahapan pembuatan sistem, perancangan yang telah dirancang sebelumnya diimplementasikan ke dalam bentuk program atau aplikasi yang akan dibangun Sistem pakar ini dibuat dengan menggunakan aplikasi Android Studio sebagai editor pemograman dan menggunakan database jenis MySQL sebagai penyimpanan datanya.

\subsection{Pengujian Sistem}

Pengujian aplikasi atau sistem adalah bagian yang penting dalam pembangunan sebuah perangkat lunak. Pengujian ditujukan untuk menemukan kesalahan-kesalahan pada sistem dan memastikan sistem yang dibangun telah sesuai dengan rencana sebelumnya. Pengujian yang dilakukan pada pengujian aplikasi ini adalah pengujian fungsional menggunakan metode black box testing. Pengujian yang dilakukan pada pengujian fungsional yaitu pengujian versi Android dan pengujian fungsi dari menu aplikasi.

\section{HASIL DAN PEMBAHASAN}

\subsection{Hasil}

Hasil dari penelitian ini berupa aplikasi sistem pakar identifikasi penyakit serta pengendaliannya pada tanaman cabai dengan metode SAW berbasis Android. Aplikasi ini berjalan pada handphone yang telah didukung oleh sistem operasi Android dengan sistem operasi yang digunakan minimal Lollipop atau versi 5.0 yang dapat memudahkan masyarakat (user) dalam menentukan suatu penyakit dari gejala yang ditunjukkan oleh tanaman cabai berdasarkan sistem pakar dengan perhitungan metode SAW. Dalam aplikasi yang dibangun ini terdapat informasi mengenai data penyakit yang terjadi pada tanaman cabai beserta cara pengendaliannya, dan 
penentuan penyakit berdasarkan gejala yang terdapat pada tanaman cabai. Adapun pembahasan mengenai implementasi dan hasil pengujian dari perancangan aplikasi sistem pakar identifikasi penyakit serta pengendaliannya pada tanaman cabai dengan metode SAW berbasis Android yang telah dirancang sebelumnya adalah dijelaskan pada sub pokok pembahasan.

\subsection{Hasil}

\subsubsection{Hasil Implementasi}

Hasil Implementasi rancangan sistem terdiri dari 6 tampilan halaman:

\section{a. Halaman Splash Screen}

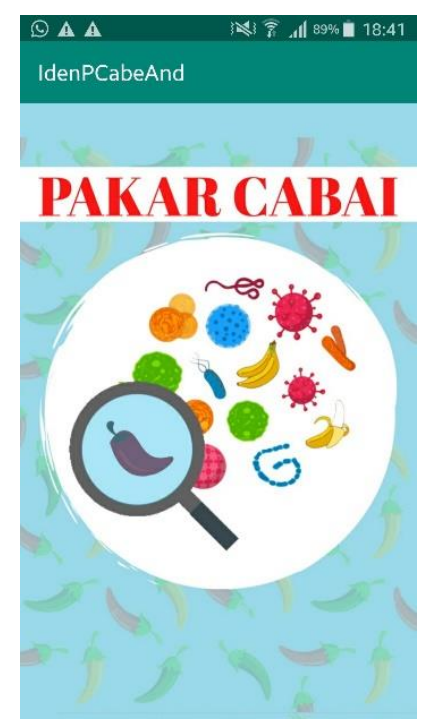

Gambar 1. Halaman Splash Screen

Gambar 1 menampilkan halaman utama sistem. Splash screen akan tampil di awal sebelum masuk ke halaman utama ketika user menggunakan atau membuka aplikasi sistem pakar diagnosa penyakit tanaman cabai ini.

\section{b. Halaman Utama}

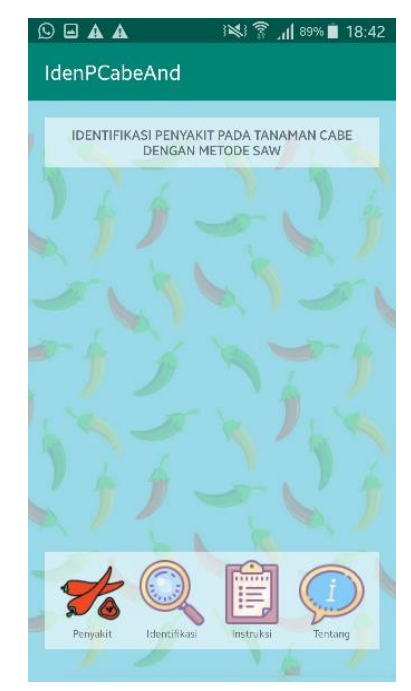

Gambar 2. Halaman Daftar Isi 
Vol 9 No. 1 , 2021

(C2021 Ilmu Komputer Unila Publishing Network all rights reserved

Jurnal Komputasi

Gambar 2 halaman utama akan muncul ketika user membuka aplikasi ini. Halaman utama aplikasi terdiri dari 5 (lima) menu, yaitu menu penyakit, identifikasi penyakit, history, instruksi dan tentang aplikasi.

\section{c. Halaman Penyakit}

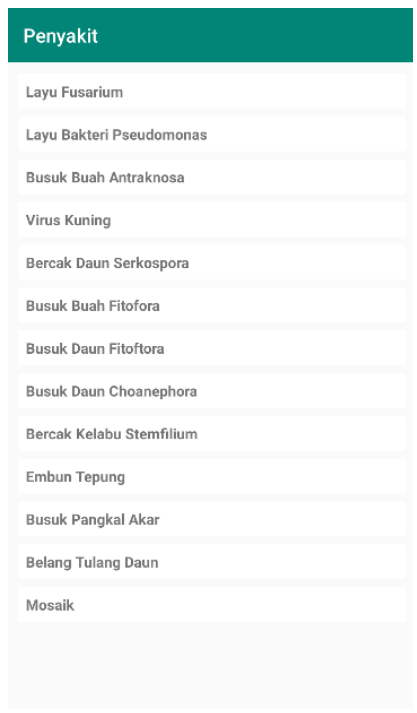

Gambar 3. Halaman Penyakit

Gambar 3 menampilkan Halaman penyakit bersikan tentang jenis-jenis penyakit yang ada pada tanaman cabai. Terdapat 13 jenis penyakit tanaman cabai yang ada pada aplikasi ini.

dari 5 (lima) menu, yaitu menu penyakit, identifikasi penyakit, history, instruksi dan tentang aplikasi.

\section{d. Halaman Identifikasi Penyakit}

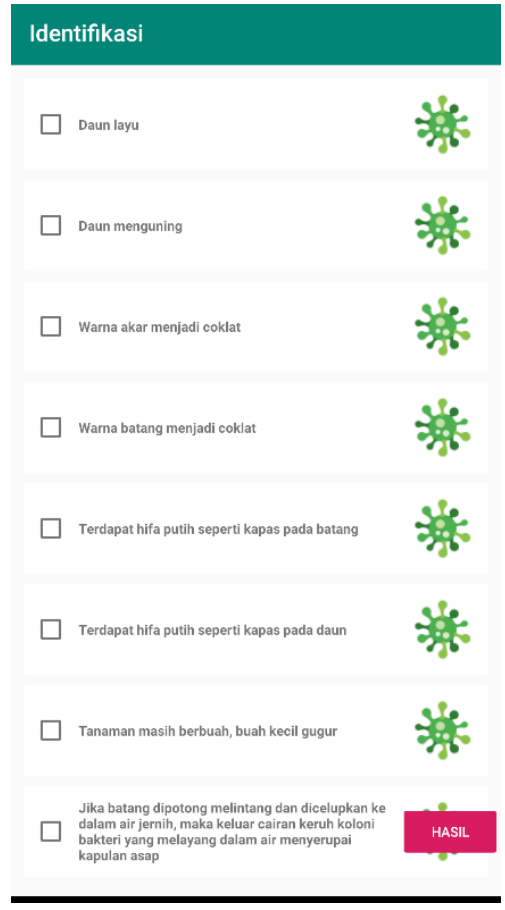

Gambar 4. Halaman Identifikasi Penyakit 
(C2021 Ilmu Komputer Unila Publishing Network all rights reserved

Gambar 4 menampilkan halaman penyakit bersikan tentang jenis-jenis penyakit yang ada pada tanaman cabai. Terdapat 13 jenis penyakit tanaman cabai yang ada pada aplikasi ini. Halaman identifikasi berisikan gejalagejala penyakit yang ditimbulkan oleh tanaman cabai. Ketika user mencentang gejala yang ditimbulkan, maka user mendapatkan informasi mengenai penyakit yang ditimbukan dari gejala tersebut.

\section{e. Halaman Hasil Identifikasi Penyakit}

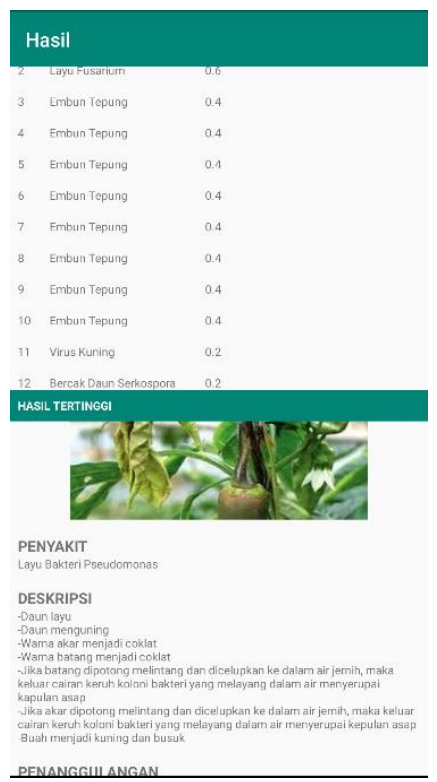

Gambar 5. Halaman Hasil Identifikasi Penyakit

Gambar 5 menampilkan halaman ketika menekan tombol hasil, maka muncul deskripsi hasil persentase yang telah dihitung oleh sistem dari gejala-gejala yang telah dipilih oleh user.

\section{f. Halaman Tentang Aplikasi}

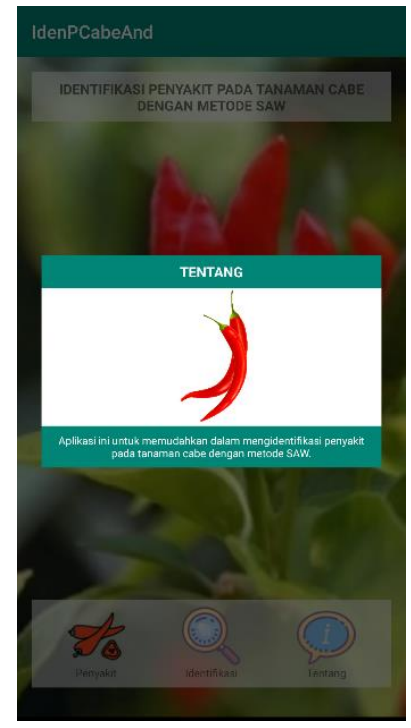

Gambar 6. Halaman Tentang Aplikasi 
Gambar 6 ketika user masuk ke dalam halaman tentang aplikasi, maka sistem memunculkan deskripsi mengenai tentang pembuat aplikasi.

\section{KESIMPULAN}

Kesimpulan yang diperoleh dari penelitian yang telah dilakukan adalah aplikasi dapat memberikan informasi berupa deskripsi mengenai jenis penyakit yang menyerang tanaman cabai beserta cara pengendaliannya serta aplikasi dapat memberikan kemudahan bagi masyarakat (pengguna) dalam mendapatkan solusi dari suatu gejala penyakit tanaman cabai yang ditimbulkan menggunakan perhitungan metode SAW.

\section{DAFTAR PUSTAKA}

[1] R. Dewi, Profil Komuditas Barang Kebutuhan Pokok dan Barang Penting Komuditas Cabai., Jakarta: Direktorat Jendral Perdagangan Dalam Negeri Kementrian Perdagangan, 2016.

[2] S. Kusumadewi, Artifical Intelligence : Teknik dan Aplikasinya. Edisi 1, Yogyakarta: Graha Ilmu, 2011.

[3] A. Anshori, Rancang Bangun Sistem Pakar Untuk Mendiagnosa Penyakit Tanaman Cabai Dengan Metode Forward Chaining, Lampung: Universitas Lampung, 2013, p. 47.

[4] A. Muslim, "Sistem Pakar Diagnosa Hama dan Penyakit Cabai Berbasis Teorema Bayes," JUTISI, vol. 4, no. 3, pp. 797-876, 2015.

[5] M. Fuljana, "Expert System of Chili Plant Disease Diagnosis Using Forward Chaining Method on Android," IJACSA, vol. 8, no. 11, pp. 70- 75, 2017. 